\title{
Delay Reduction for Digital Control System of High Power Permanent- magnet Synchronous Motor Based on Multiple Sampling Method
}

\author{
Mu Shujia ${ }^{1, a}$, Sun Guobin ${ }^{1}$, Zhang Jiabo ${ }^{1}$, Zhang Xinyu ${ }^{1}$, Wang Xiaofan ${ }^{2, b}$ \\ ${ }^{1}$ CRRC Qingdao Sifang Rolling Stock Research Institute Co., LTD., Qingdao, 266031, China \\ ${ }^{2}$ School of Electrical Engineering, Beijing Jiaotong University, Beijing, 100044, China \\ ae-mail: mushujia8247@163.com, be-mail: xfwangbjtu@163.com
}

Keywords: Multiple Sampling; Delay reduction; Digital control; Permanent-magnet synchronous motor (PMSM)

\begin{abstract}
Digitally controlled permanent-magnet synchronous motors (PMSMs) exhibit bandwidth limitations imposed by delay. In high power applications such as rail transit, the negative impact of delay is particularly serious due to the low switching frequency of the inverter. In this paper, the causes and effects of time delay are analyzed, and the sampling delay is greatly reduced by using multiple sampling method. Test results are given to verify the effectiveness and reliability of the proposed method.
\end{abstract}

\section{Introduction}

In recent years, with the development of rail transit, digital control of permanent-magnet synchronous motors (PMSMs) appears to be a very popular research topic due to the advantages of high power density and high efficiency. Under the consideration of reducing switching loss, the switching frequency of the traction inverter is very low, which is usually a few hundred hertz. Therefore, the bandwidth of the control system of PMSM is mainly limited by the sampling delay related to the digital pulse-width modulation (PWM).

Predictive control method[1-5] can improve the transient-state performance of current control, but the steady-state performance is not good when the switching frequency is low. A possible way to reduce sampling delay is multiple sampling[6-9], while keeping the same switching frequency, the sampling frequency is increased and the control algorithm is executed several times instead of only once. Multiple sampling method is applied in the control of the active filter and the DC-DC converter, and better performance is obtained in [8] and [9].

In this paper, we build the model of the PMSM control system firstly, and analyze the causes and effects of delay. The multiple sampling method is adopted to reduce the sampling delay. Finally, the effectiveness of the compensation method is verified by tests on high power experiment platform.

\section{Model of PMSM}

Clark and Park transformations are used to convert three-phase stator current into excitation current and torque current which control flux and torque respectively. For the voltage-type inverter system, equations of PMSMs in the $d$-q-axis are as follows:

$$
\begin{aligned}
& u_{\mathrm{d}}=\left(R+L_{\mathrm{d}} s\right) i_{\mathrm{d}}+e_{\mathrm{q}} \\
& e_{\mathrm{q}}=-L_{\mathrm{q}} i_{\mathrm{q}} p \omega_{\mathrm{r}} \\
& u_{\mathrm{q}}=\left(R+L_{\mathrm{q}} s\right) i_{\mathrm{q}}+e_{\mathrm{d}} \\
& e_{\mathrm{d}}=\left(\psi_{\mathrm{f}}+L_{\mathrm{d}} i_{\mathrm{d}}\right) p \omega_{\mathrm{r}} \\
& T_{\mathrm{e}}=\frac{3}{2} p\left[\psi_{\mathrm{f}} i_{\mathrm{q}}+\left(L_{\mathrm{d}}-L_{\mathrm{q}}\right) i_{\mathrm{d}} i_{\mathrm{q}}\right]
\end{aligned}
$$

Where $u_{\mathrm{d}}$ and $u_{\mathrm{q}}$ are $d$-axis voltage and $q$-axis voltage. $i_{\mathrm{d}}$ and $i_{\mathrm{q}}$ are $d$-axis current and 
$q$-axis current. $L_{\mathrm{d}}$ and $L_{\mathrm{q}}$ are $d$-axis inductance and $q$-axis inductance. $\omega_{\mathrm{r}}$ is electrical angular velocity of motor. $\psi_{\mathrm{f}}$ is the rotor flux and $R$ is the stator resistance. In this paper, the zero $d$-axis current control strategy is adopted, when $i_{\mathrm{d}}=0$, the PMSM torque equation is shown below:

$$
T_{\mathrm{e}}=\frac{3}{2} p \psi_{\mathrm{f}} i_{\mathrm{q}}
$$

The rotor flux $\psi_{\mathrm{f}}$ can be considered as a constant value. It can be seen from (2) that the electromagnetic torque of the motor is proportional to the $q$-axis current which is similar to the character of a DC motor.

The basic scheme of PMSM application contains double closed loop. The interior loop is the current loop while the outer one may be torque loop or speed loop. The current commands are generated by the torque/speed regulator, and the current regulator sends out the voltage commands. PI contoller is generally used for following current reference.

\section{Multiple Sampling Method for PMSM System}

Fig.1 (a) shows the time sequence of PWM operation in conventional digital control system, including sampling and calculation, PWM updating and PWM output, where $T_{\mathrm{s}}$ is the switching period of PWM. We get sampling and start calculation at the time of (k-1) $T_{\mathrm{s}}$, then the PWM duty cycle will be updated at the time of $\mathrm{k} T_{\mathrm{s}}$. So it can be seen that the sampling delay $T_{\mathrm{c}}$ between sampling and PWM updating is a sampling period, that is, $T_{\mathrm{c}}=T_{\mathrm{s}}$. In addition, the inverter also need a half cycle to convert the duty cycle signal to the motor terminal voltage, so the PWM output delay $T_{\mathrm{PWM}}=0.5 T_{\mathrm{s}}$. It is visible that the total delay of the current loop in the conventional digital control system is $T_{\mathrm{d}}=T_{\mathrm{C}}+T_{\mathrm{PWM}}=1.5 T_{\mathrm{s}}$.

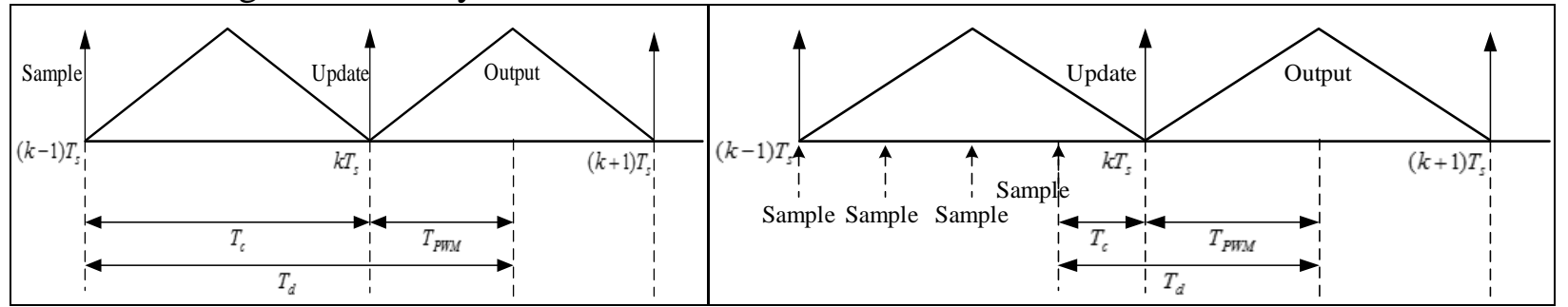

(a) Conventional sampling method

(b) Multiple sampling method

Fig.1. Time sequence of PWM operation

In order to reduce time delay, multiple sampling method is adopted in this paper. In this method, sampling frequency is higher than switching frequency. There are $m(m=1,2,3 \cdots)$ sample points during one switching period (that is $T_{\mathrm{C}}=T_{\mathrm{s}} / \mathrm{m}$ ) and latest data will be used to update the duty cycle signal of PWM. The time sequence of multiple sampling method is shown in Fig.1 (b) (with $m=4$ as an example). In this mode, the total delay of the current loop is reduced to $T_{\mathrm{d}}=T_{\mathrm{c}}+T_{\mathrm{PWM}}=0.5 T_{\mathrm{s}} *(2+m) / \mathrm{m}$.

For example, when the sampling frequency is set to four times the switching frequency, that is, $m=4$, the total delay of the system can be reduced by $50 \%$ compared to that in traditional sampling method.

Assuming that the $d$-axis and the $q$-axis of the PMSM are completely decoupled, only the $q$-axis current loop is analyzed in this paper (with $i_{\mathrm{d}}=0$ ).

The transfer function of PMSM G(s) can be derived from (1):

$$
G(s)=\frac{1}{R+L_{\mathrm{q}} s}
$$

The transfer function of PI current controller is:

$$
F(s)=K_{\mathrm{P}}+\frac{K_{\mathrm{I}}}{s}
$$

Where $K_{\mathrm{I}}, K_{\mathrm{P}}$ are the proportion and integral coefficient, respectively.

The transfer function of delay can be described as: 


$$
G_{\mathrm{d}}(s)=\frac{1}{T_{\mathrm{d}} s+1}
$$

Then the $q$-axis current control structure is shown in Fig.2.

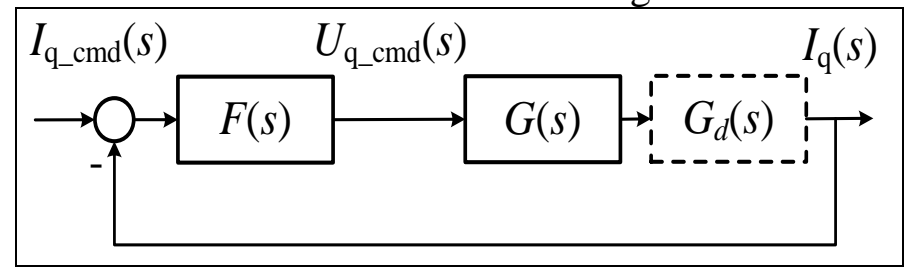

Fig.2. Block diagram of current loop ( $q$-axis)

The open-loop transfer function of current loop without delay is:

$$
G_{1}(s)=G(s) F(s)=\frac{K_{\mathrm{I}}}{R} \frac{1+K_{\mathrm{P}} s / K_{\mathrm{I}}}{s\left(1+L_{\mathrm{q}} s / R\right)}
$$

Parameter selection of the PI controller is count for much to the dynamic performance. In this paper, we set $K_{\mathrm{p}} / K_{\mathrm{i}}=L_{\mathrm{q}} / R$ so that the pole $\left(-L_{\mathrm{q}} / R, 0\right)$ can be eliminated by the zero point $\left(-K_{\mathrm{p}} / K_{\mathrm{i}}, 0\right)$. Obviously, in the ideal system without delay, the bandwidth of the controller can be theoretically infinite with proper parameters.

Considering the impact of the delay, the open-loop transfer function of current loop is:

$$
G_{2}(s)=G(s) F(s) G_{\mathrm{d}}(s)=\frac{K_{\mathrm{I}}}{R} \frac{1+K_{\mathrm{P}} s / K_{\mathrm{I}}}{s\left(1+T_{\mathrm{d}} s\right)\left(1+L_{\mathrm{q}} s / R\right)}
$$

Generally, electromagnetic time constant of the motor is far bigger than the delay, that is, $L_{\mathrm{q}} / R>>T_{\mathrm{d}}$. We set $K_{\mathrm{p}} / K_{\mathrm{i}}=L_{\mathrm{q}} / R$ to eliminate the larger pole $\left(-L_{\mathrm{q}} / R, 0\right)$, then the closed-loop transfer function can be derived as (8) with $K_{\mathrm{P}}=L_{\mathrm{q}} / 2 T_{\mathrm{d}}, K_{\mathrm{I}}=R / 2 T_{\mathrm{d}}$.

$$
G_{\mathrm{c}}(s)=1 /\left(2 T_{\mathrm{d}}^{2} s^{2}+2 T_{\mathrm{d}} s+1\right)
$$

According to (8), we get the bode diagram of the current control system which is shown in Fig. 3 with variable $m=1,2,3,4,5$ when the switching frequency $f_{s}=500 \mathrm{~Hz}$, respectively. It can be seen that the bandwidth of the system increase with the decrease of the delay. The phase lag caused by the delay in the current loop can be reduced by the using of the multiple sampling method.

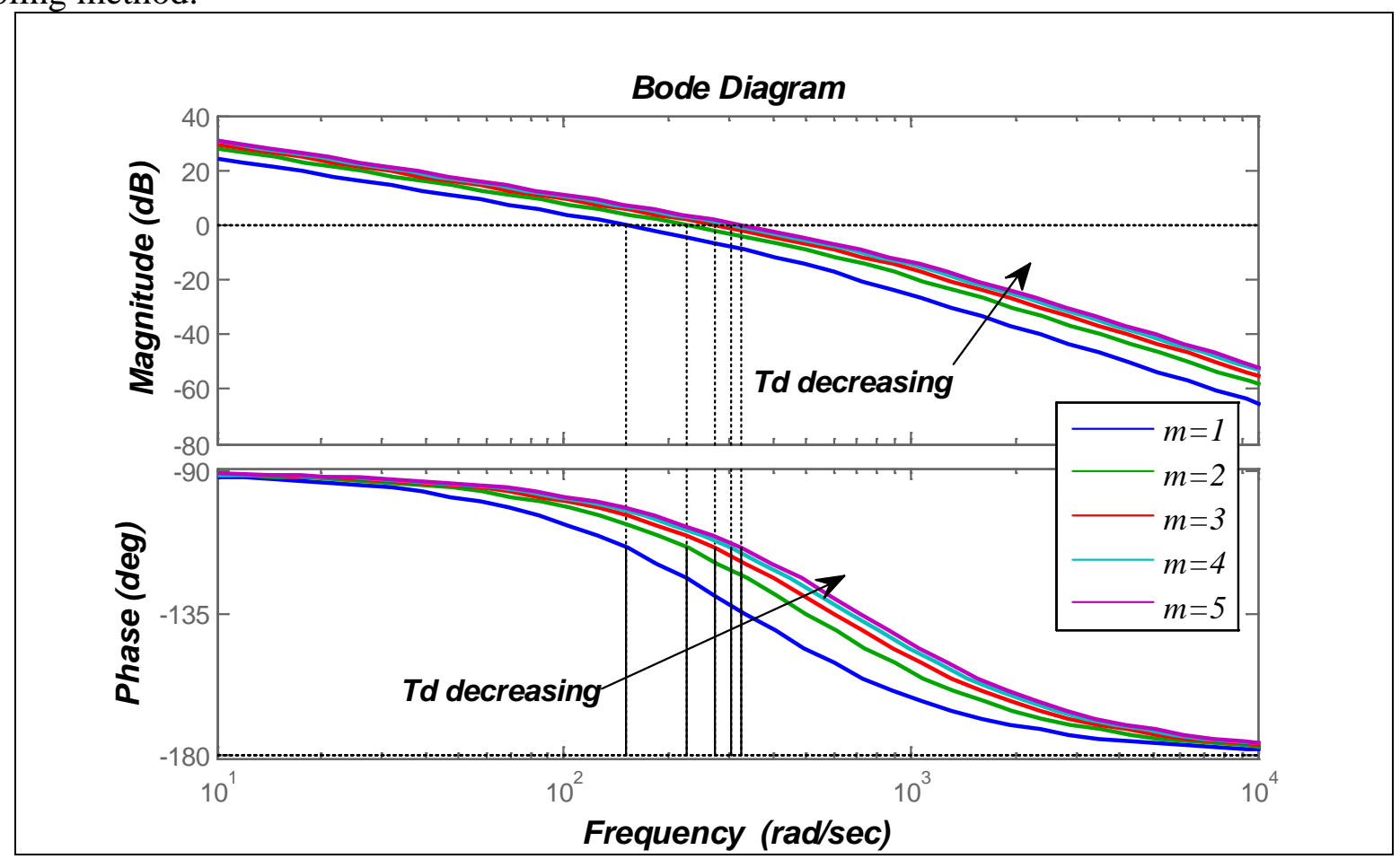

Fig.3. Bode diagram of the current control system with variable $m$ 


\section{Experimental Results}

In this paper, we set up the experimental platform of PMSM based on DSPTMS320VC33+FPGA, PMSM and the load motor (IM) are driven by two traction inverter respectively, which shared the dc-bus of $1500 \mathrm{~V}$. The setups and diagram of the experimental platform are shown in Fig.4.

Parameters of the PMSM are shown in Tab.1. Execute the test in the following two modes respectively:

Mode 1: Sampling frequency is same as the switching frequency, $f_{\mathrm{c}}=f_{\mathrm{s}}=500 \mathrm{~Hz}$;

Mode 2: Use multiple sampling method, $m=4, f_{\mathrm{c}}=4 * f_{\mathrm{s}}=2000 \mathrm{~Hz}$;

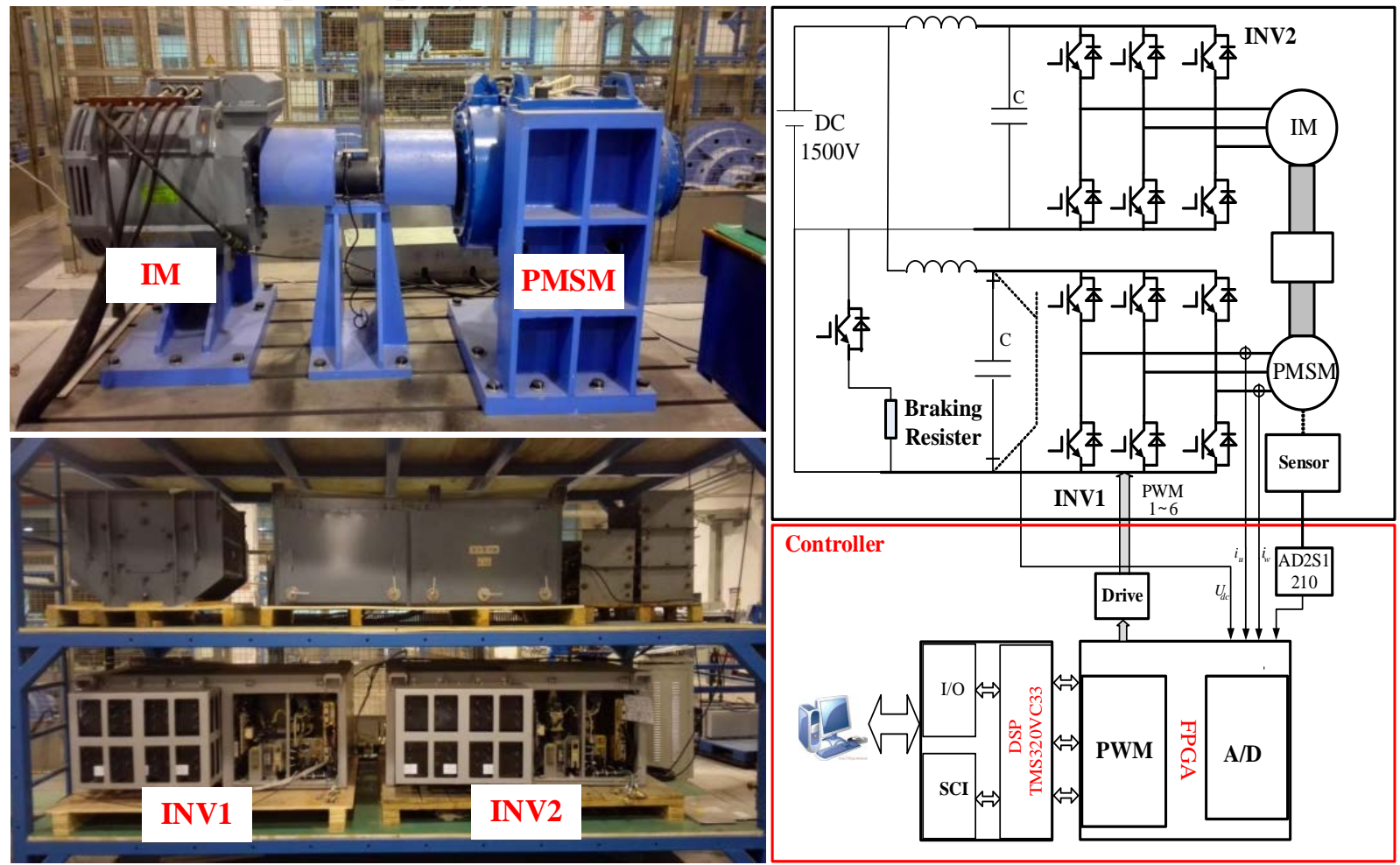

Fig.4. Setups and diagram of the experimental platform

Tab.1 Parameters of PMSM

\begin{tabular}{cc}
\hline Motor Parameters & Value \\
\hline Rated power & $300 \mathrm{~kW}$ \\
Rated voltage & $1100 \mathrm{~V}$ \\
Rated current & $169 \mathrm{~A}$ \\
Rotor flux & $1.35 \mathrm{~Wb}$ \\
Pole-pairs & 2 \\
Inductance ( $d$-axis) & $5 \mathrm{mH}$ \\
Inductance ( $q$-axis) & $15 \mathrm{mH}$ \\
Stator resistance & $0.1 \Omega$ \\
\hline
\end{tabular}

Operation process of the test: The speed of the PMSM is controlled by the load motor, which remains a constant value (300r/min). A step-up of the $q$-axis current command $(0 \rightarrow$ $20 \mathrm{~A})$ is given at $t=0.1 \mathrm{~s}$. While a step-down of the $q$-axis current command $(20 \rightarrow 0 \mathrm{~A})$ is given at $t=0.3 \mathrm{~s}$.

The current response in mode 1 is shown in Fig.5. The current rise to the maximum when the time is $41 \mathrm{~ms}$, while the steady state current has a larger range of fluctuation. The current response in mode 2 is shown in Fig.6. The rise time of the current to the maximum reduced to 26.5ms. Besides, the steady state current fluctuation of Mode 2 is smaller than Mode 1.By the comparison of current responses of the two modes, we can see that multiple sampling method can reduce the current response time. 


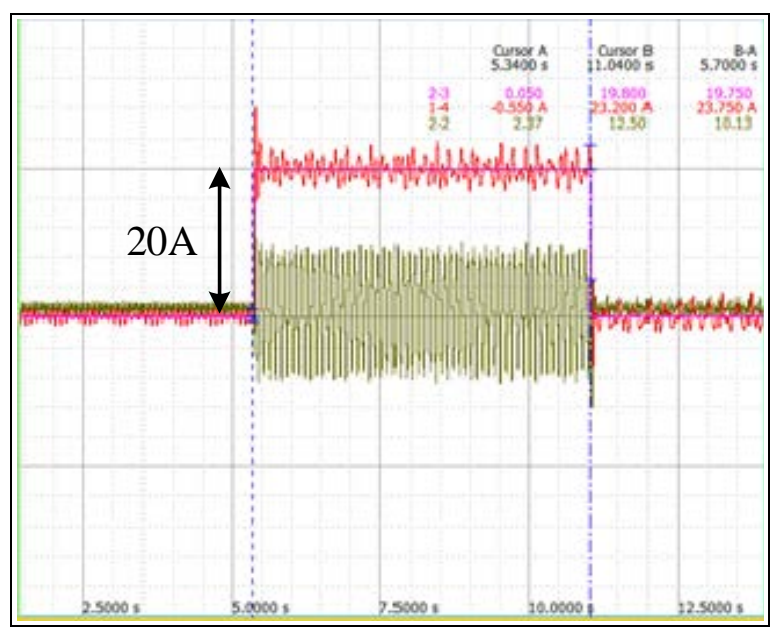

(a) Step response

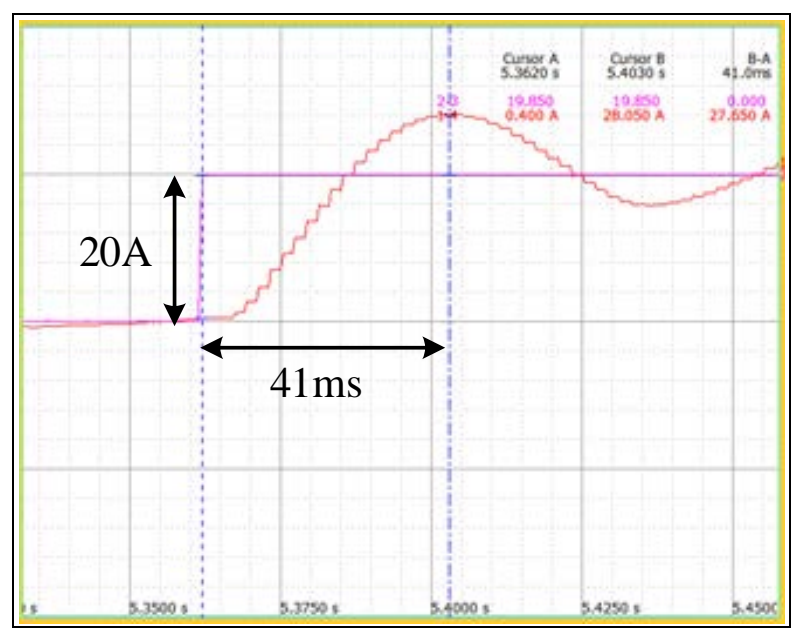

(b) Step-up response [zoom in]

Fig.5. Current response in mode 1

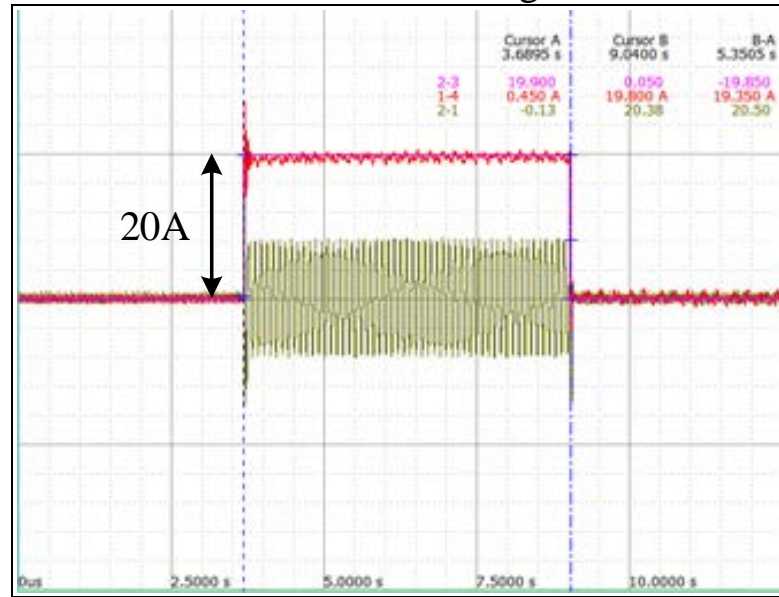

(a) Step response

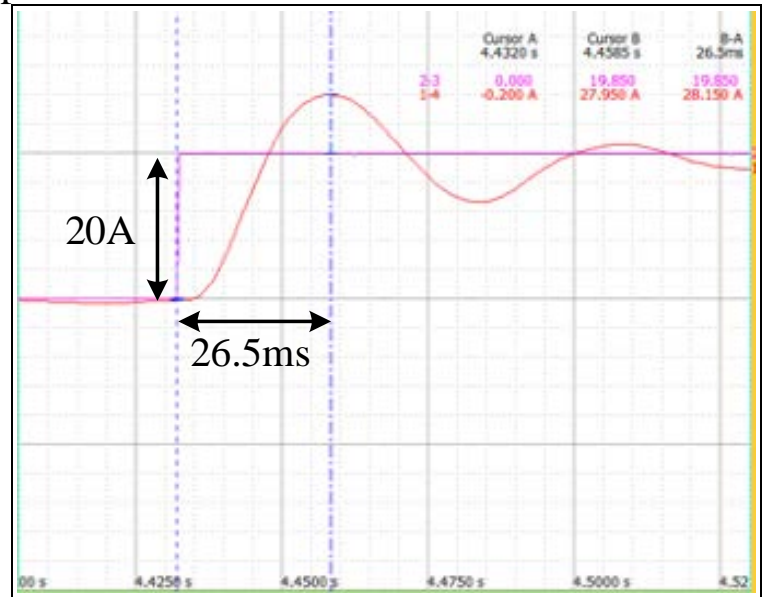

(b) Step-up response [zoom in]

Fig.6. Current response in mode 2

\section{Conclusions}

In this paper, high power PMSM and its digital control system are modeled, and the causes and effects of the delay problem are analyzed. The sampling time delay has been greatly reduced by using multiple sampling method. The improved dynamic performance of current output in transient states is verified by experimental results.

In the implementation of PMSM, we have to set aside enough time for computation so that the parameter $m$ cannot be infinite. Therefore, sampling delay is still exists even with the multiple sampling method. The delay compensation method of multiple sampling systems is worth further study in the future.

\section{References}

[1] Türker T, Buyukkeles U, Bakan A F. A Robust Predictive Current Controller for PMSM Drives[J]. IEEE Transactions on Industrial Electronics, 2016, 63(6):3906-3914.

[2] Moon H T, Kim H S, Youn M J. A discrete-time predictive current control for PMSM[J]. IEEE Transactions on Power Electronics, 2003, 18(1):464-472.

[3] Moon H T, Youn M J. Predictive current control for PMSM with consideration of calculation delay[J]. Electronics Letters, 2001, 37(24):1488-1489.

[4] Preindl M, Schaltz E. Sensorless Model Predictive Direct Current Control Using Novel Second-Order PLL Observer for PMSM Drive Systems[J]. IEEE Transactions on Industrial 
Electronics, 2011, 58(9):4087-4095.

[5] Jeong S J, Song S H. Improvement of predictive current control performance using online parameter estimation in phase controlled rectifier[J]. Power Electronics, IEEE Transactions on, 2007, 22(5): 1820-1825.

[6] Teng G, Xiao G, Zhang Z, et al. Application of high-sampling-frequency control in low-switching-frequency Lcl-filtered system[C]// Ecce Asia Downunder. 2013:566-570.

[7] Hoffmann N, Fuchs F W, Dannehl J. Models and effects of different updating and sampling concepts to the control of grid-connected PWM converters - A study based on discrete time domain analysis[C]// - European Conference on Power Electronics and Applications. 2011:1-10.

[8] Corradini L, Mattavelli P. Analysis of multiple sampling technique for digitally controlled dc-dc converters[C]// 2006:1-6.

[9] Corradini L, Stefanutti W, Mattavelli P. Analysis of multisampled current control for active filters[J]. Industry Applications IEEE Transactions on, 2008, 44(6):1785-1794. 